
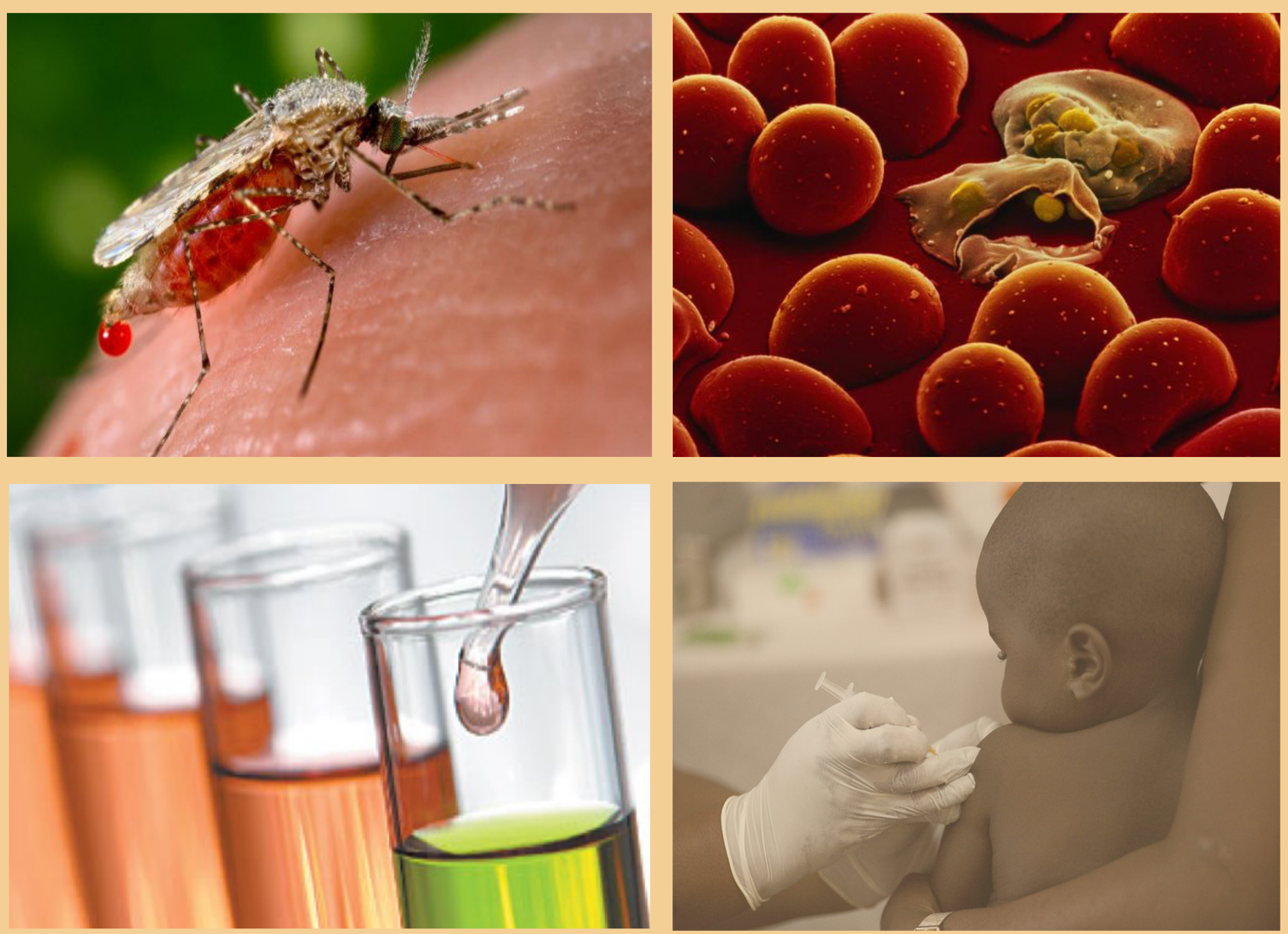

Ana Patrícia dos Santos Freitas

\title{
Progress in the Development of a Malaria Vaccine
}

Monografia realizada no âmbito da unidade de Estágio Curricular do Mestrado Integrado em Ciências Farmacêuticas, orientada pela Professora Doutora Maria do Céu Sousa e apresentada à Faculdade de Farmácia da Universidade de Coimbra

Julho 2016

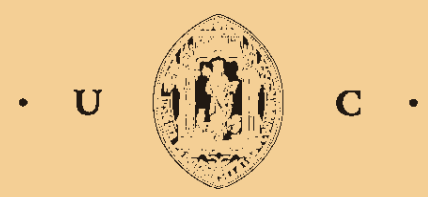




\section{Ana Patrícia dos Santos Freitas}

\section{Progress in the Development of a Malaria Vaccine}

Monografia realizada no âmbito da unidade de Estágio Curricular do Mestrado Integrado em Ciências Farmacêuticas, orientada pela Professora Doutora Maria do Céu Sousa e apresentada à Faculdade de Farmácia da Universidade de Coimbra

Julho 2016 
Eu, Ana Patrícia dos Santos Freitas, estudante do Mestrado Integrado em Ciências Farmacêuticas, com $\circ \mathrm{n}^{\circ} 201014618 \mathrm{I}$, declaro assumir toda a responsabilidade pelo conteúdo da Monografia apresentada à Faculdade de Farmácia da Universidade de Coimbra, no âmbito da unidade de Estágio Curricular.

Mais declaro que este é um trabalho original e que toda e qualquer afirmação ou expressão, por mim utilizada, está referenciada na Bibliografia desta Monografia, segundo os critérios bibliográficos legalmente estabelecidos, salvaguardando sempre os Direitos de Autor, à exceção das minhas opiniões pessoais.

Coimbra, 14 de Julho de 2016

Ana Patrícia dos Santos Freitas 


\section{AGRADECIMENTOS}

\section{Quero prestar os meus mais profundos e sinceros agradecimentos a todas}

as pessoas que contribuíram para a conclusão de mais uma etapa importante da minha vida.

Tenho que agradecer:

À minha Família, mãe, pai e irmão, pelo amor e carinho, pelo apoio incondicional, pela paciência, pela confiança que sempre depositaram em mim e por sempre me incentivarem a superar-me a mim mesma. $\bigcirc$ meu percurso académico não foi $\circ$ mais linear mas foi recheado de bons momentos e, cada um deles, contribuiu para a pessoa que sou hoje. Nada do que alcancei seria possível sem a minha Família, devo-lhes tudo.

Ao Filipe, por toda amizade e amor, companheirismo, apoio, motivação e por acreditar em mim e nas minhas capacidades, mesmo quando eu própria duvido.

À minha Tutora da Monografia Professora Doutora Maria do Céu Sousa, pelo seu apoio, disponibilidade, sabedoria e orientação.

Aos meus amigos Mariana Pinto, Carolina Dias, Tiago Lima, Sofia Salgado, Inês Roldão, Inês Barejo, André Mateus, Diogo Braz, Fábio Carvalho, pela sua amizade, companheirismo, boadisposição, apoio e carinho. Vivemos juntos bons momentos que vou guardar sempre no meu coração. Todos eles, de uma maneira ou de outra contribuíram para o meu crescimento enquanto pessoa.

Um agradecimento especial à Mariana Pinto, à Carolina Dias e ao Tiago Lima por estarem sempre presentes nos momentos mais difíceis e por me terem ajudado a ultrapassar as dificuldades que surgiram durante o meu percurso académico. São amigos que levo comigo para a vida.

A Coimbra, cidade do conhecimento e das tradições, pelos ensinamentos, pelas experiências e pelas boas memórias que me proporcionou. 


\section{TABLE OF CONTENTS}

LIST OF ABBREVIATIONS

ABSTRACT/RESUMO 2

I. INTRODUCTION 3

2. MALARIA 4

2.I. Epidemiology and Prophylaxis $\quad 4$

2.2. The Plasmodium Life Cycle 5

2.3. Natural and Vaccine induced Immunity 6

3. APPROACHES TO A MALARIA VACCINE

3.I. Vaccine Targets 7

3.2. Plasmodium vivax 9

3.2.I. Leading Vaccine Candidates $\quad 10$

3.3. Plasmodium falciparum II

3.3.I. Pre-erythrocytic Stage Vaccines 12

3.3.2. Blood-stage Vaccines 13

3.3.3. Transmission-blocking Vaccines $\quad 14$

3.4. Considerations about Malaria Vaccines in Development $\quad$ I5

4. OVERVIEW OF RTS,S/ASOICLINICAL DEVELOPMENT 17

4.I. Malaria Vaccine Technology Roadmap (MVTRM) 17

$\begin{array}{ll}\text { 4.2. Circumsporozoite Protein and RTS,S } & 17\end{array}$

4.3. Phase III Program $\quad$ I8

4.4. Regulatory, Policy, and Financing Pathway 21

4.5. Post-approval Program/Phase IV Studies 22

4.6. The Future of RTS,S 22

5. REGULATORY BASIS FOR THE DEVELOPMENT OF A MALARIA VACCINE 23

5.I. World health organization (WHO) - Policy Recommendation and Prequalification 23

5.2. European Medicines Agency (EMA) - Article 58 Procedure 25

5.3. Global Strategies to implement a Malaria Vaccine 25

6. CONCLUDING REMARKS 26

7. BIBLIOGRAPHY 27 


\section{LIST OF ABBREVIATIONS}

ACTs - Artemisinin-Combination Therapies

AMA - Apical Membrane Antigen

CHMP - Committee for Medicinal Products for Human Use

CSP - Circumsporozoite Protein

EMA - European Agency of Medicines

EPI - Expanded Programme on Immunization

FDA - Food and Drug Administration

GFATM - Global Fund to Fight Aids, Tuberculosis and Malaria

GMP - Global Malaria Programme

GSK - GlaxoSmithKline

IPT $\mathrm{p}$ - Intermittent Preventive Treatment in Pregnancy

IRS - Indoor Residual Spraying

IVBD - Immunization, Vaccines and Biologicals Department

JTEG - Joint Technical Expert Group

LLINs - Long-Lasting Insecticide Nets

MA - Marketing Authorization

MPAC - Malaria Policy Advisory Committee

MSP - Merozoite Surface Protein

MVTRM - Malaria Vaccine Technology Roadmap

NIAID - National Institute of Allergy and Infectious Diseases

ODA - Orphan Drug Act

PATH - Programme for Appropriate Technology in Health

Pf - Plasmodium falciparum

Pv - Plasmodium vivax

RDls - Rapid Diagnostic Tests

SAGE - Strategic Advisory Group of Experts

SMC - Pregnancy and Seasonal Malaria Chemoprevention

SPZ - Plasmodium Sporozoite

TBV - Transmission Blocking Vaccine

VIS - Vaccine Investment Strategy

WHO - World Health Organization 


\section{ABSTRACT}

Malaria is a public health problem and in the year of 2015 were estimated 214 million cases worldwide. Malaria is caused by a parasite of the Genus Plasmodium sp. and it is transmitted by the bite of the Anopheles insect. Although there are numerous malaria control measures implemented, the mortality rate is still too high. A tool that would be crucial towards eradicating malaria would be a vaccine. During the development of malaria vaccines three main approaches have emerged according to the phase of the parasite's life cycle in which they operate: pre-erythrocytic vaccines, blood-stage vaccines and transmission blocking vaccines. The development of vaccines aimed at parasites is a complex process due to the multiplicity of antigens which are presented during different stages of the parasite's life cycle. However there has been progress and there is a erythrocytic vaccine aimed at $P$. falciparum that is well advanced in clinical trials, the RTS, S. The RTS, S was approved by the World Health Organization (WHO) and also received a positive assessment by the European Medicines Agency (EMA) and is currently in a pilot phase of implementation after having been the subject of several recommendations by the Technical Committee of WHO. Key-words: Malaria, Plasmodium, P. falciparum, Vaccine, Erradication, RTS,S, WHO

\section{RESUMO}

A Malária é um problema de Saúde Pública e em 2015 estimaram-se 214 milhões de casos a nível mundial. A Malária é provocada pelo parasita do Género Plasmodium sp. e é transmitida pela picada do insecto Anopheles. Apesar da implementação de inúmeras medidas de controlo da Malária, a taxa de mortalidade continua demasiado alta. Uma ferramenta que seria crucial na erradicação da Malária seria uma vacina. No desenvolvimento de vacinas para a Malária surgiram três abordagens principais de acordo com a fase do ciclo de vida do parasita na qual atuam: vacinas que atuam no ciclo eritrocitário; vacinas que atuam no ciclo hepático; vacinas que atuam no ciclo esporogónico. O desenvolvimento de vacinas contra parasitas é um processo complexo devido à multiplicidade de antigénios que são apresentados durante as diferentes fases do ciclo de vida do parasita. Contudo tem havido progressos e existe uma vacina eritrocitária contra a espécie $P$. falciparum que avançou bastante nos ensaios clínicos, a RTS,S. A RTS,S foi aprovada pela Organização Mundial de Saúde (OMS) e recebeu também uma avaliação positiva por parte da Agência Europeia de Medicamentos (EMA) e encontra-se neste momento numa fase piloto de implementação após ter sido alvo de recomendações pelo Comité Técnico da OMS.

Palavras-chave: Malária, Plasmodium, P. falciparum, Vacina, Erradicação, RTS,S, OMS 


\section{INTRODUCTION}

Malaria is a life-threatening disease caused by parasites of the Plasmodium genus. In 2015 , approximately 3.2 billion people - nearly half of the world's population - were at risk of malaria. ${ }^{[I]}$ Despite recent reductions in the overall malaria case incidence, malaria remains a leading cause of morbidity and mortality in the developing world. Furthermore in many parts of the world, the parasites have developed resistance to a number of antimalarial agents. $^{[2]}$ Although there are key interventions to control malaria that have been implemented, these measures alone have not been enough to eradicate malaria. ${ }^{[3]}$ Vaccines would be the ideal addition to the existing armamentarium of anti-malaria tools. However, malaria is caused by parasites, and parasites are much more complex in terms of their biology than the viruses and bacteria for which we have vaccines, passing through multiple stages of development in the human host, each stage expressing hundreds of unique antigens. ${ }^{[4]}$

There are three main approaches concerning Malaria vaccines targeting different stages in the life cycle of the Malaria parasite: (i) pre-erythrocytic vaccines; (ii) blood-stage vaccines; and (iii) transmission-blocking vaccines. ${ }^{[3,4]}$

The current leading malaria vaccine candidate is the RTS,S (consisting of fusion between a portion of the $P$. falciparum-derived circumsporozoite protein (CSP) and the hepatitis B surface antigen), which has been demonstrated to induce reasonably good protection but not high enough to eradicate malaria. ${ }^{[3]}$ Despite self-assembly into $\mathrm{HBsAg}$ virus-like particles, non-adjuvant RTS,S is weakly immunogenic and requires an adjuvant to improve the magnitude and duration of the immune responses to CSP. The Adjuvant System selected, ASOI, consists of two immunostimulants in a liposome formulation. ${ }^{[5]}$

The malaria vaccine, RTS,S/ASOI, received a positive scientific opinion from the European Medicines Agency under Article 58 of Regulation (EC) No 726/2004, indicating that, in their assessment, the quality of the vaccine and the risk-benefit profile is favourable from a regulatory perspective. The vaccine requires administration of four doses and the extent to which the protection demonstrated in the Phase 3 trial can be replicated in the context of the routine health system is uncertain. Pilot implementation of the first malaria vaccine was recommended by WHO advisory groups (SAGE and the MPAC). WHO is now actively working with financing bodies, and the malaria vaccine clinical trials partnership (including PATH and GSK) to mobilise the financial support for the pilots, and to finalise design of the pilot implementation programme. ${ }^{[6]}$ 


\section{MALARIA}

Malaria is a major global infectious disease caused by parasitic protozoans of the genus Plasmodium, which includes: P. falciparum, $P$. vivax, $P$. ovale spp., $P$. malariae and $P$. knowlesi. Of the five Plasmodium species that infect humans, Plasmodium falciparum and Plasmodium vivax cause the majority of cases, and P. falciparum is the most virulent and responsible for the majority of deaths. Malaria is transmitted by the bite of infected female Anopheline mosquitoes and the intensity of transmission depends on factors related to the parasite, the vector, the human host, and the environment. ${ }^{[2,7]}$

Severe morbidity and mortality from $P$. falciparum malaria result from sequestration of infected erythrocytes and associated vital organ dysfunction. Sequestration causes microvascular obstruction-related brain pathology, metabolic acidosis compounded by severe anemia due to accelerated erythrocyte destruction, hypoglycemia, circulatory shock, and in older children and adults, renal failure and pulmonary edema. ${ }^{\left[{ }^{[]}\right.}$

\section{I. Epidemiology and Prophylaxis}

According to the latest WHO data, an estimated 438000 people died of malaria in 2015 , with over $90 \%$ of these deaths occurring in sub-Saharan Africa, and nearly all of the others occurring in South-East Asia and South America. ${ }^{[6]}$

Almost all malaria deaths are caused by Plasmodium falciparum. Most of these deaths occur in African children younger than 5 years. Adults who have lived in areas with high malaria transmission since childhood and remain resident in such areas are generally not at risk of death from malaria. Worldwide, the number of new episodes of clinical malaria in 2015 is estimated to be around 214 million. ${ }^{[6]}$

P. vivax is the dominant Plasmodium species in endemic areas outside sub-Saharan Africa. Vaccine development efforts have focused on preventing illness from $P$. falciparum and, to a lesser extent, on $P$. vivax. ${ }^{[8]}$

With regard to prophylaxis, in most African countries, substantial malaria control activities have been implemented and include the widespread deployment of long-lasting insecticidal nets (LLINs), the use of indoor residual spraying (IRS) of insecticides in some settings, prompt diagnosis using quality-assured rapid diagnostic tests (RDTs), treatment with highly effective artemisinin-combination therapies (ACTs), intermittent preventive treatment (IPTP) in pregnancy and seasonal malaria chemoprevention (SMC) in highly seasonal areas. ${ }^{[8]}$ 
WHO recognizes the importance of malaria due to $P$. falciparum as a major cause of morbidity and mortality, particularly in sub-Saharan Africa, and the essential role of existing malaria control measures in significantly reducing the burden of disease in recent years. Nevertheless, despite considerable scale-up of these interventions, malaria transmission, morbidity and mortality remain high in many endemic settings. Prevention needs to be strengthened still further and new tools are needed. ${ }^{[8]}$

Despite impressive gains over the last 15 years in reducing the mortality associated with malaria, it remains a public health emergency. New interventions, such as vaccines, are needed to ensure that previous gains serve as a foundation for future progress. Vaccines have the potential to prevent severe disease and death in those most vulnerable, and to accelerate elimination and eradication by breaking the cycle of parasite transmission. ${ }^{[9]}$

\subsection{The Plasmodium Life Cycle}

The malaria parasite requires mosquitoes and human hosts to complete its life cycle and goes through several developmental stages to survive in the human host (Fig. I). During its two-host life cycle, $P$. falciparum undergoes 10 morphological transitions in five different host tissues. The cycle in humans includes (i) the pre-erythrocytic stage, which is the first stage of infection in humans with inoculation of sporozoites to infect the hepatocytes; (ii) the erythrocytic stage, which involves asexual reproduction of the parasite in the blood to cause the clinical symptoms of the disease; and (iii) the gametocyte stage, which enables sexual reproduction of the parasite in the mosquito and further transmission. ${ }^{[3]}$

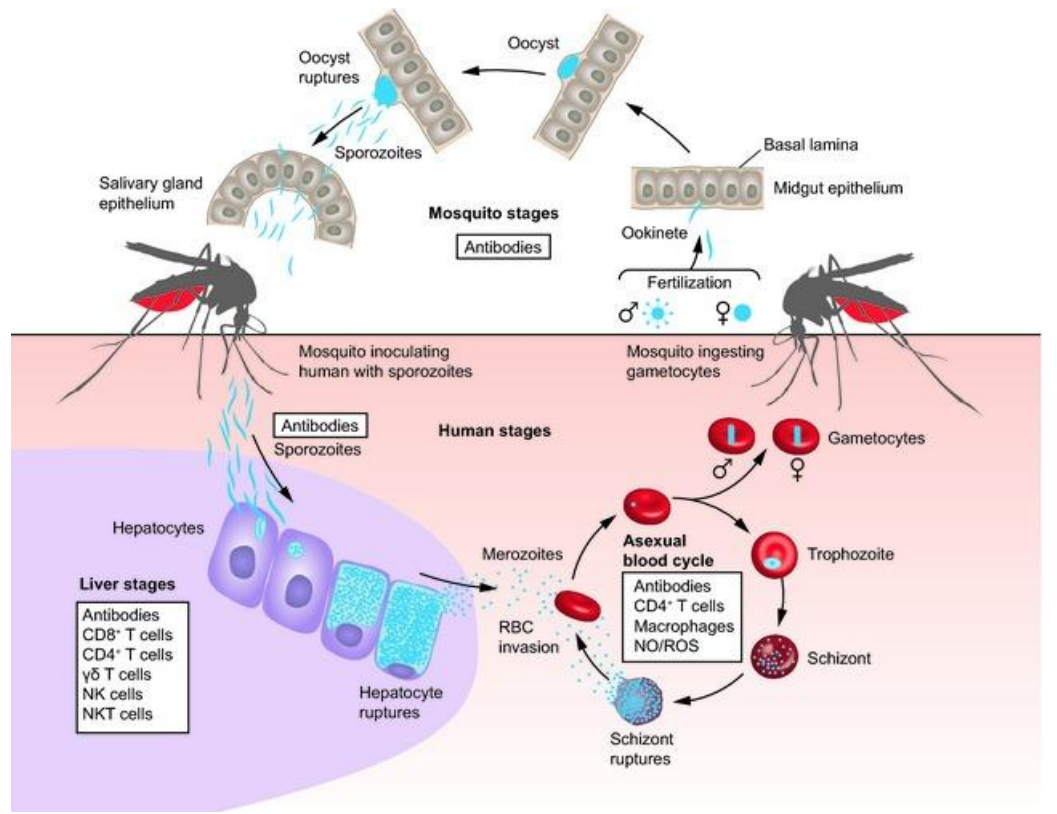

Fig. I - The life cycle of $P$. falciparum. ${ }^{[3]}$ 
The pre-erythrocytic stage begins when an infected female Anopheles mosquito inoculates sporozoites into the skin or into the blood stream of humans during a blood meal. Sporozoites circulate transiently in the bloodstream before invading hepatocytes, in which the asexual cycle takes place. When sporozoites reach the liver parenchyma, they continue to migrate through several hepatocytes before finally infecting one of them. This migration contributes for malaria infections in two different ways: by activating sporozoites for infection and by increasing the susceptibility of host hepatocytes. After a week, rupture of the merosomes within the lung microvasculature releases thousands of infectious merozoites into the bloodstream where they invade circulating erythrocytes and initiate the clinically important intraerythrocytic cycle of asexual replication during the following $48 \mathrm{~h}$.

The intraerythrocytic cycle is responsible for all the clinical symptoms associated with the disease. After 24-32 h, when young parasites mature from rings to the trophozoite stage, infected erythrocytes adhere to endothelial cells in the microcirculation of various organs (known as sequestration) causing cerebral malaria if sequestered in the brain. The trophozoites will eventually mature into schizonts, which finally rupture and release 16-32 daughter merozoites that can invade fresh red blood cells to restart the asexual life cycle.

Some parasites inside the erythrocytes differentiate into male and female gametocytes. Upon ingestion by a feeding female mosquito, the male and female gametes undergo fertilization in the mosquito midgut to form a zygote and subsequently a motile ookinete. Ookinetes penetrate the midgut epithelial cells and rest between the midgut epithelium and the basal lamina to form oocysts. The oocysts undergo a complex asexual development stage, which eventually generates infective sporozoites that can be introduced into the human host at the next blood meal via the mosquito saliva, thereby ensuring the continuation of the parasite life cycle. ${ }^{[3]}$

\subsection{Natural and Vaccine induced Immunity}

Natural exposure to $P$ falciparum gradually elicits, in human hosts, short-lived strainspecific malaria immunity: first to severe disease and death, and then to mild disease. Repeated infections are required to maintain immunity, which is both antibody and T-cell based. Immunity acquired in malaria-endemic areas is likely to be mediated by an integration of low to moderate responses to many antigens.

The malaria parasite possesses several mechanisms of immune invasion in the host, such as intracellular parasitism, adherence of infected red blood cells to endothelial cells or 
antigenic variation and the ability to overcome these mechanisms is a challenge for the development of effective malaria vaccines. ${ }^{[10]}$

The aim with most vaccines is to induce antibody and T-cell responses to one or a few antigens, but for effective vaccination these will need to be of greater magnitude, duration, and strain-transcendence than in naturally acquired immunity. Antigenic variation occurs in some important blood-stage malaria antigens, and there is a possibility that vaccination could select for escape mutants.

T-cell responses have been neglected, in particular for blood-stage vaccine development; which responses are necessary is little known or understood, except for the need to produce T-cell help for an antibody response. An alternative, ambitious, long-term approach is to use a cocktail of many antigens to attempt to mimic natural immunity, but this could lead to a complex and costly product. ${ }^{[1]}$

\section{APPROACHES TO A MALARIA VACCINE}

There are three general approaches to developing malaria vaccines, targeting different stages of the parasite lifecycle, each of which is supported by biological evidence that protective immune responses are attainable.

Pre-erythrocytic vaccines aim to induce antibodies that block hepatocyte invasion by sporozoites and/or cell-mediated immune responses that target infected hepatocytes. Whole parasite and subunit vaccine approaches, evaluated in controlled human malaria infection (CHMI) and/or field efficacy studies, have proven to successfully induce PE-stage immunity.

The scientific rationale supporting the development of asexual blood-stage vaccines is rooted in the observation that naturally acquired immunity can be passively transferred to susceptible individuals.

Finally, development of transmission blocking vaccines is based on studies in avian and primate models where immunization with extracellular gametes totally suppressed parasite infectivity to mosquitoes on a subsequent bloodmeal. ${ }^{[7]}$

\section{I. Vaccine Targets}

An ideal malaria vaccine requires three essential features: (i) multiple components that will induce an effective immune response to the different stages of the malaria infection (sporozoites, infected hepatocytes and asexual and sexual stages); (ii) multiple epitopes that 
are restricted to presentation by different major histocompatibility complex (MHC) molecules to overcome genetic diversity and antigenic variation; and (iii) multiimmunogenicity inducing more than one type of immune response, including cellmediated and humoral components. Such a multicomponent vaccine should increase the probability of a sustainable and effective host response. ${ }^{[3]}$

The ideal vaccine for the pre-erythrocytic stage would induce high titres of functional antibodies against sporozoites to prevent all parasites entering the liver stage, and induce potent cytotoxic T-lymphocyte immunogenicity against the liver stage to kill infected hepatocytes, while not harming the human host. ${ }^{[1]}$ The Pf circumsporozoite protein (CSP), present on the sporozoite surface, expressed by early liver forms and exported into the cytoplasm of hepatocytes, is the antigen targeted by the RTS,S malaria vaccine candidate. The sporozoite plays a central role in the parasite life cycle, from the maturing Plasmodium oocyst in the midgut of the definitive host to initial infection of the intermediate host.. ${ }^{[5]} \mathrm{CSP}$ was the first malaria protein to be cloned and has been an early target of malaria vaccine research. It was shown to be a key target of protective immunity induced by irradiated sporozoite vaccines in animal models. ${ }^{[4]}$

Blood-stage vaccines are designed to elicit antiinvasion (preventing the invasion of the erythrocyte by the merozoite) and antidisease responses (targeting the infected erythrocyte for destruction by the host's immune system). ${ }^{[3]}$ Numerous antigens that are unique to either the merozoite (e.g. the merozoite surface antigens, such as AMA-I, MSP I, 2 and 3) or to the infected erythrocyte (erythrocyte-associated surface antigens, such as RESA, SERA5 and EBA 175) are potential erythrocytic-stage vaccine antigens. The net effect of such erythrocyte-stage immune responses could be to limit or ameliorate the blood-stage manifestations of the malaria infection. ${ }^{[12]}$

Transmission blocking immunity relies on functional antibodies against surface membrane proteins on sexual/sporogonic stages or mosquito midgut antigens. Prefertilization antigens are expressed in gametocytes (such as Pf25, Pf28, Pf230 and Pf45/48) in the human host but only become accessible for functional antibody binding once gametocytes emerge from the red blood cells to form gametes in the mosquito midgut. Naturally acquired- or experimentally-induced antibodies can bind to gametes, thereby preventing fertilization and zygote formation. Pre-fertilization antigens expressed in humans can induce antibodies after natural infection thereby creating the possibility to boost and/or enhance vaccine induced antibody titers and longevity. Post-fertilization transmission blocking target antigen expression occurs in the mosquito midgut in zygotes and 
ookinetes. ${ }^{[13]}$ The main Antigens and Targets of potential Malaria Vaccines are summarized in the following table.

Table I- Main Antigens and Targets of Potential Malaria Vaccines ${ }^{[3,7, \mid 4]}$

\begin{tabular}{ccc}
\hline Antigens & Targets & Vaccines \\
\hline CSP & Sporozoite & $\begin{array}{c}\text { Pre-Erythrocytic Vaccines } \\
\text { Whole sporozoite vaccines }\end{array}$ \\
AMA I; MSP I, 2, 3; GRURP & Merozoite & Assexual Blood Stage Vaccines \\
RESA, SERA5, EBA 175 & Erythrocyte & \\
Pfs25, Pfs28, Pfs230, Pfs45/48 & Gametocyte & Sexual Stage Vacccines \\
CSP, PvTRAP & Sporozoite & \\
SSP2/MTRAP, DBP & Merozoite & \\
MSPI, AMAI & Gametocyte & \\
Pvs25 and Pvs28 & & \\
\hline
\end{tabular}

\subsection{Plasmodium vivax}

P. falciparum and $P$. vivax malaria pose the greatest public health challenge. $P$. vivax has a wider geographical distribution than $P$. falciparum because it can develop in the Anopheles mosquito vector at lower temperatures, and can survive at higher altitudes and in cooler climates. Although $P$. vivax can occur throughout Africa, the risk of infection with this species is quite low there because of the absence in many African populations of the Duff $y$ gene, which produces a protein necessary for $P$. vivax to invade red blood cells. In many areas outside Africa, such as South and South-east Asia, Pacific islands, Central and South America, infections due to $P$. vivax cause substantial morbidity with more than $50 \%$ of malaria cases. $^{[6,15]}$

The unique biology of $P$. vivax, including its ability to form latent hypnozoites that emerge months to years later to cause blood stage infections, early appearance of gametocytes before clinical symptoms are apparent and a shorter development cycle in the vector makes elimination of $P$. vivax using standard control tools difficult. The availability of an effective vaccine that provides protection and prevents transmission would be a valuable tool in efforts to eliminate $P$. vivax. The development of such a vaccine will likely require combination of multiple antigens that provide synergy to achieve high efficacy. ${ }^{[15]}$ 


\subsection{Leading Vaccine Candidates}

Efforts to develop vaccines against different stages of $P$. vivax have been underway over past two decades. Table 2 summarizes key information about the various vaccine candidates that have reported progress toward clinical development. ${ }^{[15]}$

VMP00I is a recombinant PvCSP chimeric antigen, that contains the repeat (R) sequences of the two major PvCSP alleles, VK210 (9 repeats) and VK247 (I repeat) fused to $\mathrm{N}$ - and C-terminal conserved regions of PvCSP from the VK2IO allele. ${ }^{[16]} \mathrm{VMPOOI}$ formulated with ASOIB was tested in a Phase I/lla study in malaria naïve healthy volunteers and it was found to be safe and induced high titer antibody responses. ${ }^{[15]}$

Based on the identification of B and T cell epitopes in PvCSP, long synthetic peptides (LSPs), N (N-terminal), R (Repeat), and C (carboxyl terminal) have also been developed for assessment as vaccine candidates. ${ }^{[17]}$ The three LSPs have been tested in Phase I clinical trials both individually, formulated with Montanide ISA720 in escalating doses (10 $\mu \mathrm{g}, 30 \mu \mathrm{g}$ and $100 \mu \mathrm{g} /$ dose), and as a mixture of 3 LSPs (50 and $100 \mu \mathrm{g} /$ dose of mixture of peptides) formulated with Montanide ISA 720 and Montanide ISA 5I. Antibodies were elicited against each of the peptides in the mixture and recognized native PfCSP on the surface of sporozoites. The Montanide ISA5I formulation elicited higher antibody titers and inferferon production. ${ }^{[15]}$

The chimpanzee adenovirus ChAd63 and the modified vaccinia virus Ankara (MVA) have been used to express $P$. vivax thrombospondin-related adhesive protein (PvTRAP). Priming with recombinant ChAd63 expressing PvTRAP followed by boosting with recombinant MVA expressing PvTRAP induced high anti-body titers and T cell responses in mice. ${ }^{[18]}$

Parasite proteins expressed on surface of zygote (Pvs25) and ookinete (Pvs28) stages each contain four cysteine-rich epidermal growth factor-like domains with a C-terminal glycosylphosphatidylinositol (GPI) anchor. Pvs25H, a vaccine formulation of Pvs25 with Alhydrogel was tested in a dose-escalation $(5,20,80 \mu g / d o s e)$ Phase I trial in healthy volunteers. The formulations were found to be safe and induced high titer antibodies in a dose dependent manner. However, only a 20-30\% reduction in the number of infected mosquitoes was observed with sera from immunized individuals in membrane feeding assays. Though the vaccine provided proof of principle for development of a transmission blocking vaccine based on Pvs25, higher levels of transmission blocking activity are needed for an effective deployable vaccine. ${ }^{[15,19]}$ 
Table 2- $P$. vivax vaccine candidates under development $\mathfrak{t}^{[15]}$

\begin{tabular}{cccc}
\hline Vaccine candidate & $\begin{array}{c}\text { Development } \\
\text { Phase }\end{array}$ & Life cycle stage & Antigen \\
\hline VMP00I & Phase I/lla & Liver stage & PvCSP \\
CSV-S,S & Pre-clinical & Liver stage & PvCSP \\
PvCSP-LSP & Phase I & Liver stage & PvCSP \\
$\begin{array}{c}\text { ChAd63-PvTRAP/MVA- } \\
\text { PvTRAP }\end{array}$ & Phase I & Liver stage & PvTRAP \\
PvDBPII & Pre-clinical & Blood stage & PvDBP \\
PvDBPII-DEKnull & Pre-clinical & Blood stage & PvDBP \\
ChAd63-PvDBPII/MVA- & Pre-clinical & Blood stage & PvDBP \\
PvDBPII & Pre-clinical & Blood stage & PvMSPI \\
PvMSPII9 & Pre-clinical & Blood stage & PvAMAI \\
ChAd63-PvAMAI/MVA- & Pre-clinical & Blood stage & PvAMAI \\
PvAMAI & Phase I & Trans. Stage & Pvs25 \\
Pvs25H & Pre-clinical & Trans. Stage & Pvs28 \\
Pvs28 & Pre-clinical & Mosquito midgut Ag & AnAPNI \\
AnAPNI & & & \\
\hline & & & \\
\hline & & &
\end{tabular}

\subsection{Plasmodium falciparum}

P. falciparum is most prevalent on the African continent, and is responsible for more than $98 \%$ of malaria mortality and has the most significant drug resistance of all the human parasites. ${ }^{[4]}$ Vaccine development efforts have focused on preventing illness from $P$. falciparum and, to a lesser extent, on $P$. vivax. ${ }^{[8]}$ Furthermore, the most progress has been made on Pf vaccines. ${ }^{[4]}$

More than $30 \mathrm{P}$. falciparum malaria vaccine candidates are at either advanced preclinical or clinical stages of evaluation, as it is shown in Table $3 .{ }^{[8]}$ Approaches that use recombinant protein antigens and target different stages of the parasite life-cycle are being developed, but only the RTS,S/ASOI vaccine has completed Phase 3 evaluation and received a positive regulatory assessment. $\mathrm{WHO}$ has developed a set of principles to ensure the quality, safety, and efficacy of recombinant vaccines targeting pre-erythrocytic and blood stage malaria parasites. ${ }^{[12]}$ 


\subsection{Pre-erythrocytic Stage Vaccines}

Research on pre-erythrocytic vaccines has quickly progressed during this last decade, and a number of new approaches are in the pipeline that could contribute to improve the second generation of malaria vaccines. Liver-stage vaccines are designed to prevent malaria in the human host. However, because of the high rate of replication of sporozoites, a single parasite may be sufficient for the infection to proceed to the blood stage. The liver stage of $P$. falciparum is an attractive therapeutic target for the development of both antimalarial drugs and vaccines, as it provides an opportunity to interrupt the life cycle of the parasite at a critical early stage. However, an efficient liver-stage vaccine must be $100 \%$ effective to protect humans with no natural immunity. Such vaccines include those containing whole killed sporozoites (whole sporozoite vaccine) and those based on antigenic portions of the circumsporozoite proteins (subunit antigens). ${ }^{[3]}$

The RTS,S, a subunit antigen malaria candidate vaccine targets the Pf circumsporozoite protein (CSP), a 412 amino acid protein (7G8 clone sequence) present on the sporozoite surface, expressed by early liver forms and exported into the cytoplasm of hepatocytes. It has a characteristic central NANP repeat region and non-repeat flanking regions with both conserved and variable segments. Functional properties have been unravelled, with conformational status determining biological activity related to parasite binding, motility, cell traversal and biochemical properties. ${ }^{[4]}$

Initial candidate vaccine constructs targeting the central repeat region of the PfCSP failed to provide substantial protection. Based on experience acquired during the development of the first genetically engineered hepatitis B vaccine, a new construct was generated at GSK and tested through collaboration with the Walter Reed Army Institute of Research. The hepatitis $B$ surface antigen $(\mathrm{HBs} A g)$ was used as carrier matrix. The repetitive immunodominant B-cell epitope from the central region (NANP repeats) and T-cell epitope containing C-terminal flanking region (CSP aminoacids 207-395 of the 3D7 clone of the NF54 strain of Pf) were fused to the $\mathrm{HbsAg}$ protein, and expressed together with free $\mathrm{HbsAg}$ in Saccharomyces cerevisiae. ${ }^{[4]}$

The new vaccine was designated RTS,S to indicate the presence of the CSP repeat region (R), T-cell epitopes ( $\mathrm{T})$ fused to the $\mathrm{HbsAg}(\mathrm{S})$ and assembled with unfused copies of HbsAg. The resulting proteins assembled into virus-like particles (VLPs), similar to those formed by the unfused $\mathrm{HbsAg}$ proteins. ${ }^{[4]}$ 
The Plasmodium sporozoite (SPZ), transmitted to the human host by female Anopheles mosquitoes, is an attractive vaccine candidate. If immune responses induced by such a vaccine could kill the SPZ during its journey from the mosquito proboscis to the liver or during development in the liver (pre-erythrocytic stages of the parasite life cycle), there would be no blood stage infection and no production of gametocytes. ${ }^{[20]}$

Sanaria Inc. has developed methods to manufacture, purify and cryopreserve aseptic Plasmodium falciparum (Pf) sporozoites (SPZ), and is using this platform technology to develop an injectable PfSPZ-based vaccine that provides high-grade, durable protection against infection with Pf malaria. Several candidate vaccines are being developed and tested: PfSPZ Vaccine, in which the PfSPZ are attenuated by irradiation, PfSPZ-Cvac, in which fully infectious PfSPZ are attenuated in vivo by concomitant administration of an anti-malarial drug and PfSPZ-GAI, in which the PfSPZ are attenuated by gene knockout. ${ }^{[20]}$

Forty-three research groups in 15 countries, organized as the International PfSPZ Consortium (I-PfSPZ-C), are collaborating to advance this program by providing intellectual, clinical, and financial support. Fourteen clinical trials of these products have been completed in the USA, Europe and Africa, two are underway and at least 12 more are planned for 20I5-2016 in the US (four trials), Germany (2 trials), Tanzania, Kenya, Mali, Burkina Faso, Ghana and Equatorial Guinea. Sanaria anticipates application to license a first generation product as early as late 2017 , initially to protect adults, and a year later to protect all persons over 6 months of age for at least six months. ${ }^{[20]}$

\subsubsection{Blood-stage Vaccines}

There are two possible classes of blood-stage vaccine: antiinvasion and anticomplication. A vaccine that could prevent invasion of red blood cells by merozoites would prevent malaria disease. ${ }^{[1]}$

At present, several blood-stage antigens are in clinical trials: apical membrane antigen I (AMAI) $)^{[21]}$, erythrocyte-binding antigen-I75 (EBA-I75) $)^{[22]}$, glutamate-rich protein $(\text { GLURP) })^{[23,24]}$, merozoite surface protein (MSP) $\mathrm{I}^{[25]}, \mathrm{MSP}^{[26]}$ and MSP3 ${ }^{[27,28]}$ and serine repeat antigen 5 (SERA5). ${ }^{[29,30]}$ All these antigens are highly expressed on the surface of merozoites. Of note, AMAI and MSPI did not demonstrate efficacy in African children, probably due to the highly polymorphic nature of the vaccine structures. Efforts to enhance the vaccine efficacy of AMAI and MSPI with novel adjuvants, using viral vector prime-boost strategies, or by combining AMAI and MSPI have been investigated. ${ }^{[3]}$ With increasing 
research in this field, new antigens with great potential as blood-stage vaccine candidates have been discovered. For example, P. Falciparum reticulocyte-binding protein homologue 5 (PfRH5) has been shown to induce inhibitory antibodies that are effective across common PfRH5 genetic variants. In addition, rhoptry-associated leucine zipper-like protein I (RALPI), which plays an important role during merozoite invasion into erythrocytes, was recognized by malaria-immune serum samples from Mali and Thailand, suggesting the potential of this protein as a blood-stage vaccine candidate. These candidates showed strong immunogenicity; therefore, it is time to proceed to Phase I/lia human trials and, if successful, they could be combined with vaccines targeting other stages of the $P$. Falciparum life cycle. ${ }^{[3]}$

The extensive genetic diversity of the parasite and the selective pressure exerted by the host's immune response are major factors to be considered in the development of effective blood-stage vaccines. How to address genetic polymorphism constitutes an important issue to be explored with regard to this group of vaccines. It has been suggested that efforts would be emphasized on antigens or constructs inducing cross-reactive immune responses, which could cover genetic diversity.

Since many antigenic targets are shared between liver- and blood-stage parasites, malaria vaccines have the potential to elicit cross-stage protection with immune mechanisms against both stages complementing and enhancing each other. Cross-stage immunity would be a powerful means to improve protective efficacy of malaria vaccines, however data to support this hypothesis are sparse. During liver-stage development both the amount of antigen and the antigenic similarity to blood-stage parasites increases. Thus as Plasmodium matures in the liver, it is potentially capable of inducing immunity not only against preerythrocytic but also against blood-stage parasites. Equally, exposure to attenuated bloodstage parasites could protect against sporozoite challenge. Future studies should therefore investigate the potential of cross-stage immunity directly. ${ }^{[3]}$

\subsubsection{Transmission-blocking Vaccines}

TBVs target antigens on gametes, zygotes and ookinetes to prevent parasite development in the mosquito midgut. The aim of these vaccines is to induce antibodies against the sexual-stage antigens to block ookinete-to-oocyst transition to stop the subsequent generation of infectious sporozoites. Of note, TBVs do not protect the recipient from contracting malaria, but could be helpful in preventing the spread of the disease. ${ }^{[3]}$ 
Although a substantial number of targets have been identified and tested in preclinical studies over the past decades, the lead vaccine candidates have not changed and include prefertilization proteins Pfs $48 / 45$ and Pfs 230 and post-fertilization antigen Pfs 25 . In a very different approach, mosquito derived targets have been identified that are involved in egress of the ookinete stages from the midgut represented by AnAPNI, also forming a starting point for SSM-VIMT development. ${ }^{[13]}$

Pfs 25 has been in the lead position since 1983 when specific and potent mAbs were shown to block transmission. Pfs 25 is a $25-\mathrm{kDa}$ GPI-anchored surface protein containing four epidermal growth factor (EGF)-like domains with 22 cysteines and IIdisulfide bonds. The protein is shed from the membrane and likely involved in ookinete adhesion and subsequent penetration of the midgut. ${ }^{[13]}$

To improve the immunogenicity, Pfs 25 was expressed as a recombinant protein that was chemically cross-linked to E. coli-expressed ExoProtein A (EPA) and delivered as a nanoparticle, in a phase I human clinical trial by the NIAID group. ${ }^{[3,13]}$

\subsection{Considerations about Malaria Vaccines in Development}

The current vaccine development pipeline is relatively diverse in terms of both the stage of parasite lifecycle targeted and the technology platforms being exploited. The global malaria vaccine portfolio is maintained at a website managed by WHO. A summary of clinical-stage vaccine approaches, by lifecycle stage, is provided below and on Table 3.

Table 3 - Development status of current clinical-stage vaccine candidates

\begin{tabular}{|c|c|c|}
\hline Candidate Vaccine & Developer & Clinical Trial \\
\hline \multicolumn{3}{|c|}{ Pre-erythrocytic Projects } \\
\hline $\begin{array}{c}\text { RTS,S/ASO IE } \\
\text { RTS,S/ASO I delayed fractional } \\
\text { third dose }\end{array}$ & GSK & $\begin{array}{l}\text { Phase IV } \\
\text { Phase Ila }\end{array}$ \\
\hline $\begin{array}{c}\text { ChAd63/MVA ME-TRAP } \\
\text { ChAd63/MVA ME-TRAP/Matrix } \\
\text { MTM }\end{array}$ & University of Oxford & $\begin{array}{c}\text { Phase II/la/llb } \\
\text { Phase lb }\end{array}$ \\
\hline PfSPZ & Sanaria, Inc. & Phase Ila/lb/llb \\
\hline $\begin{array}{l}\text { PfCelTOS FMPOI 2/ASOIB } \\
\text { PfCelTOS FMPOI 2/GLA-SE }\end{array}$ & $\begin{array}{c}\text { Office of the Surgeon General (US), } \\
\text { Department } \\
\text { of the Army (US), USAMRMC }\end{array}$ & $\begin{array}{l}\text { Phase la } \\
\text { Phase I }\end{array}$ \\
\hline CSVAC & University of Oxford & Phase lb \\
\hline $\begin{array}{c}\text { R2 I/AS0 IB } \\
\text { R2 I/Matrix-MI }\end{array}$ & University of Oxford & Phase la \\
\hline
\end{tabular}




\begin{tabular}{|c|c|c|}
\hline \multicolumn{3}{|c|}{ Blood-stage Projects } \\
\hline $\begin{array}{c}\text { GMZ2/Alhydrogel } \mathbb{} \\
\text { GMZ2 field/Alhydrogel } 尺\end{array}$ & $\begin{array}{l}\text { European Vaccine Initiative (EVI) } \\
\text { AMANET, Statens Serum Institut }\end{array}$ & $\begin{array}{l}\text { Phase la } \\
\text { Phase lb/ll }\end{array}$ \\
\hline $\begin{array}{c}\text { PfAMAl-DiCo/GLA-SE or } \\
\text { Alhydrogel } \AA\end{array}$ & Inserm & Phase I \\
\hline P27A/GLA-SE or Alhydrogel $®$ & $\begin{array}{l}\text { Centre Hospitalier Universitaire } \\
\text { Vaudois } \\
\text { (CHUV) }\end{array}$ & Phase I \\
\hline MSP3-LSPIAIOH & EVI, AMANET & Phase la/lb/llb \\
\hline SE36/AIOH & $\begin{array}{c}\text { Research Foundation for Microbial } \\
\text { Diseases of } \\
\text { Osaka University }\end{array}$ & Phase lb \\
\hline $\begin{array}{c}\text { NMRC-M3V-Ad-PfCA } \\
\text { NMRC-M3V-D/Ad-PfCA } \\
\text { prime/boost }\end{array}$ & $\begin{array}{c}\text { Office of the Surgeon General (US), } \\
\text { Department } \\
\text { of the Army (US), USAMRMC }\end{array}$ & $\begin{array}{l}\text { Phase } I / I l a \\
\text { Phase } I / I l a\end{array}$ \\
\hline PfPEBS-LSPIAIOH & Vac4All & Phase I/II \\
\hline ChAd63 RH5 \pm MVA RH5 & University of Oxford & Phase I \\
\hline PRIMVAC & Inserm & Phase la/lb \\
\hline \multicolumn{3}{|c|}{ Sexual stage Projects } \\
\hline $\begin{array}{l}\text { Pfs25-VLPIAlhydrogel } \\
\text { Pfs25-EPA/Alhydrogel }\end{array}$ & $\begin{array}{c}\text { Fraunhofer USA (FhCMB) } \\
\text { NIAID/NIH (USA) }\end{array}$ & $\begin{array}{l}\text { Phase } \mathrm{I} / \mathrm{Il} \mathrm{a} \\
\text { Phase } \mathrm{lb}\end{array}$ \\
\hline $\begin{array}{l}\text { Pfs230DIM-EPA/Alhydrogel } \\
\text { and/or Pfs25-EPA/Alhydrogel }\end{array}$ & NIAID/NIH (USA) & Phase I \\
\hline $\begin{array}{c}\text { ChAd63 Pfs25-IMX3 I 3/MVA } \\
\text { Pfs25-IMX3 I3 }\end{array}$ & University of Oxford (UK) & Phase la \\
\hline \multicolumn{3}{|c|}{ Plasmodium vivax Project } \\
\hline ChAd63/MVA PvDBP & University of Oxford & Phase la \\
\hline
\end{tabular}

The most advanced malaria vaccine candidate in development globally, RTS,S/ASOI, completed Phase III clinical testing in 20I4. This subject will be discussed later in the paper.

In recent years, preliminary evidence for vaccine-induced clinical efficacy from field studies has been generated using three blood-stage targets, P. falciparum AMAI, MSP3 and SERA5. The development of effective subunit vaccines targeting asexual blood stages has been buoyed by progress in deciphering the redundant network of merozoite invasion mechanisms for $P$. falciparum, revealing promising new vaccine targets. For $P$. vivax, the challenge of effectively targeting merozoite invasion ligands appears to be less complex, with the Duffy binding protein (DBP) representing the overwhelmingly dominant invasion ligand for ensuring reticulocyte invasion. Protein-and vector-based vaccines are expected to enter 
clinical testing over the coming years. Further, whole, attenuated blood-stage vaccines for $P$. falciparum are advancing toward clinical development based on promising preclinical data.

Clinical studies to evaluate induction of antibodies to sexual, sporogonic, and/or mosquito-stage antigens, to block human-to-mosquito transmission, have to date focused on two antigens (Pfs25and Pvs25) delivered as either recombinant proteins or via attenuated vaccinia virus; however, high levels of transmission-blocking activity have not been reported. ${ }^{[7]}$

\section{OVERVIEW OF RTS,SIASO I CLINICAL DEVELOPMENT}

\section{I. Malaria Vaccine Technology Roadmap (MVTRM)}

The MVTRM was originally launched in 2006 and focused on the urgent need for vaccines to alleviate the ongoing severe disease and death due to malaria. As such, the priority for the global malaria vaccine development efforts was on $P$. falciparum, children under 5 years of age, in sub-Saharan Africa and other highly endemic regions. The following timeline (Fig. 2) represents the efforts made by GlaxoSmithKline (GSK), since 1984 until 2015 , for the development of RTS,S. ${ }^{[5]}$

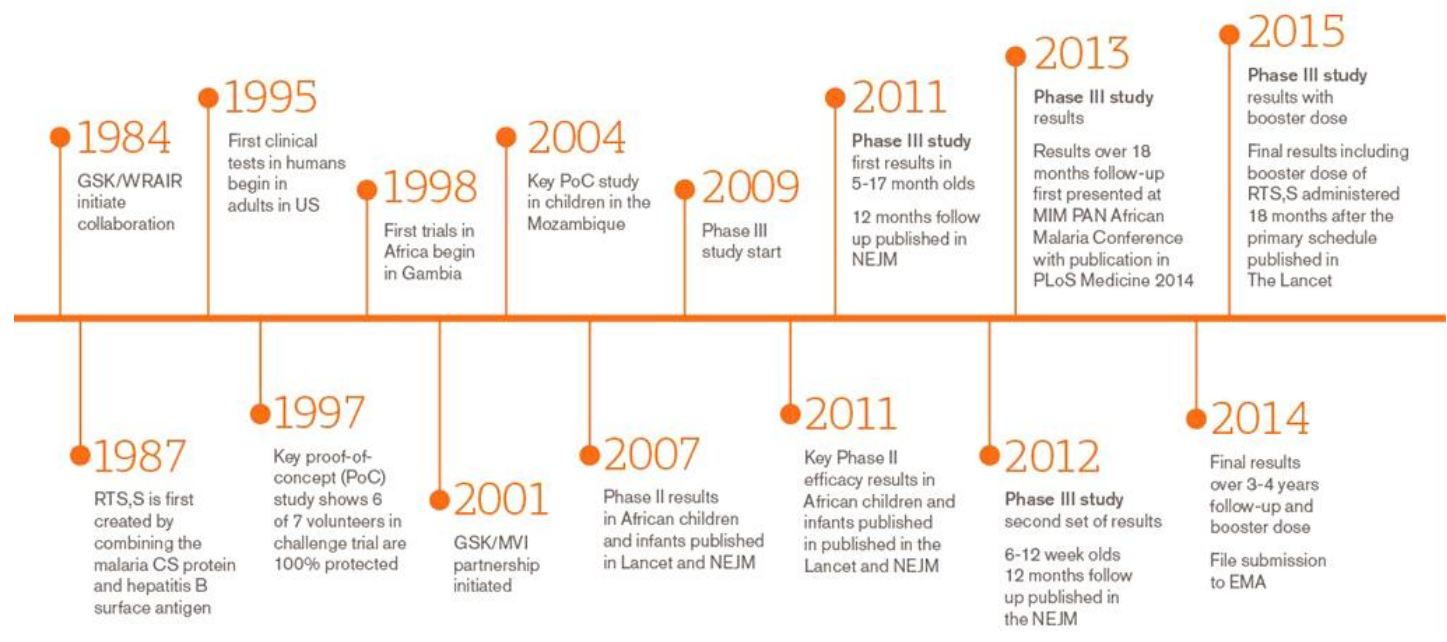

Fig. 2 - The timeline for development of RTS,S through 2015 spans 30 years. ${ }^{[32]}$

\subsection{Circumsporozoite Protein and RTS,S}

RTS,S contains 189 amino acids from CSP (NF54 199-387aa), including the last 18 NANP repeats and the C-terminus exclusive of the GPI anchor addition sequence (Fig. 3). Approximately $25 \%$ of the Hepatitis B virus surface antigen (HBsAg) monomers in RTS,S particles are genetically fused to the truncated CSP and serve as protein carriers. Despite self-assembly into $\mathrm{HBsAg}$ virus-like particles, non-adjuvant RTS,S is weakly immunogenic and 
requires an adjuvant to improve the magnitude and duration of the immune responses to CSP. The Adjuvant System selected, ASOI, consists of two immunostimulants, 3-O-desacyl4_-monophosphoryl lipid A (MPL) and QS-2I Stimulon® Adjuvant (QS-2I), in a liposome formulation. ${ }^{[5]}$

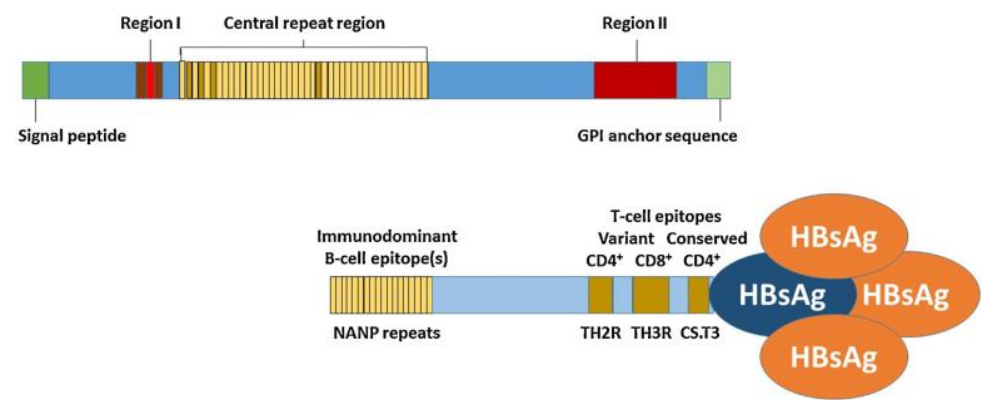

\section{Fig. 3 - Graphical depiction of circumsporozoite (CSP) and RTS,S structures ${ }^{[5]}$}

\subsection{Phase III Program}

The cornerstone of the Phase III program was a pivotal efficacy and safety trial, MALARIA-055 (NCT00866619), conducted by the RTS,S Clinical Trials Partnership at II clinical trial sites in seven African countries (one site in Burkina Faso, Gabon, Malawi and Mozambique; two sites in Ghana and Tanzania; and, three sites in Kenya). The trial started in May 2009, enrolled 15,459 infants and young children, concluded in January 20I4, and the results summary through study end posted in January 20I5. Table 5 summarizes on-going clinical trials of RTS,S in support of the pediatric indication. ${ }^{[5]}$

Table 4 - Ongoing/planned RTS,S clinical and epidemiological studies ${ }^{[5]}$

\begin{tabular}{|c|c|c|}
\hline Study Groups & Study and Objectives & $\begin{array}{c}\text { Location } \\
\text { Age at enrollment } \\
\text { Sample size }\end{array}$ \\
\hline $\begin{array}{l}\text { Pivotal Ph III efficacy and safety study } \\
\text { extension } \\
\text { Same study groups as in the primary study } \\
\text { - RTS,S/ASOI ( } 3 \text { doses) + RTS,S/ASOI booster } \\
\text { dose } \\
\text { - RTS,S/ASOI ( } 3 \text { doses) + control vaccine } \\
\text { - Control vaccine ( } 3 \text { doses })+ \text { control vaccine }\end{array}$ & $\begin{array}{l}\text { Long-term efficacy, safety and } \\
\text { immunogenicity of RTS,S/ASOI over } \\
\text { an additional 3-year period. } \\
\text { - Primary endpoint: incidence of } \\
\text { severe malaria. } \\
\text { - Secondary endpoints: clinical } \\
\text { malaria, parasite prevalence and } \\
\text { SAEs of special interest }\end{array}$ & $\begin{array}{l}\text { Tanzania, Kenya, Burkina } \\
\text { Faso } \\
\text { 5-17 months or } \\
6-12 \text { weeks } \\
3600\end{array}$ \\
\hline $\begin{array}{l}\text { Co-administration Ph IIlb study (Measles, } \\
\text { yellow fever and rubella vaccines) } \\
\text { - RTS,S/ASOI at } 6,7.5 \text { and } 9 \mathrm{~m} \text {. Yellow fever and } \\
\text { measles-rubella vaccines co-administered at } 9 \mathrm{~m} \text {. } \\
\text { - RTS,S/ASOI at } 6,7.5 \text { and } 9 \mathrm{~m} \text {, Yellow fever and } \\
\text { measles-rubella vaccines staggered at } 10 \mathrm{~m} \text {. } \\
\text { - Yellow fever and measles-rubella vaccines at } 9 \mathrm{~m} \text {. } \\
\text { All groups receive vitamin A at } 6 \mathrm{~m}\end{array}$ & $\begin{array}{l}\text { Non-inferiority of immune response } \\
\text { and safety of the RTS,S/ASOI with or } \\
\text { without co-administration of measles, } \\
\text { yellow fever and rubella vaccines }\end{array}$ & $\begin{array}{l}\text { To be determined } \\
6 \text { months } \\
700\end{array}$ \\
\hline
\end{tabular}




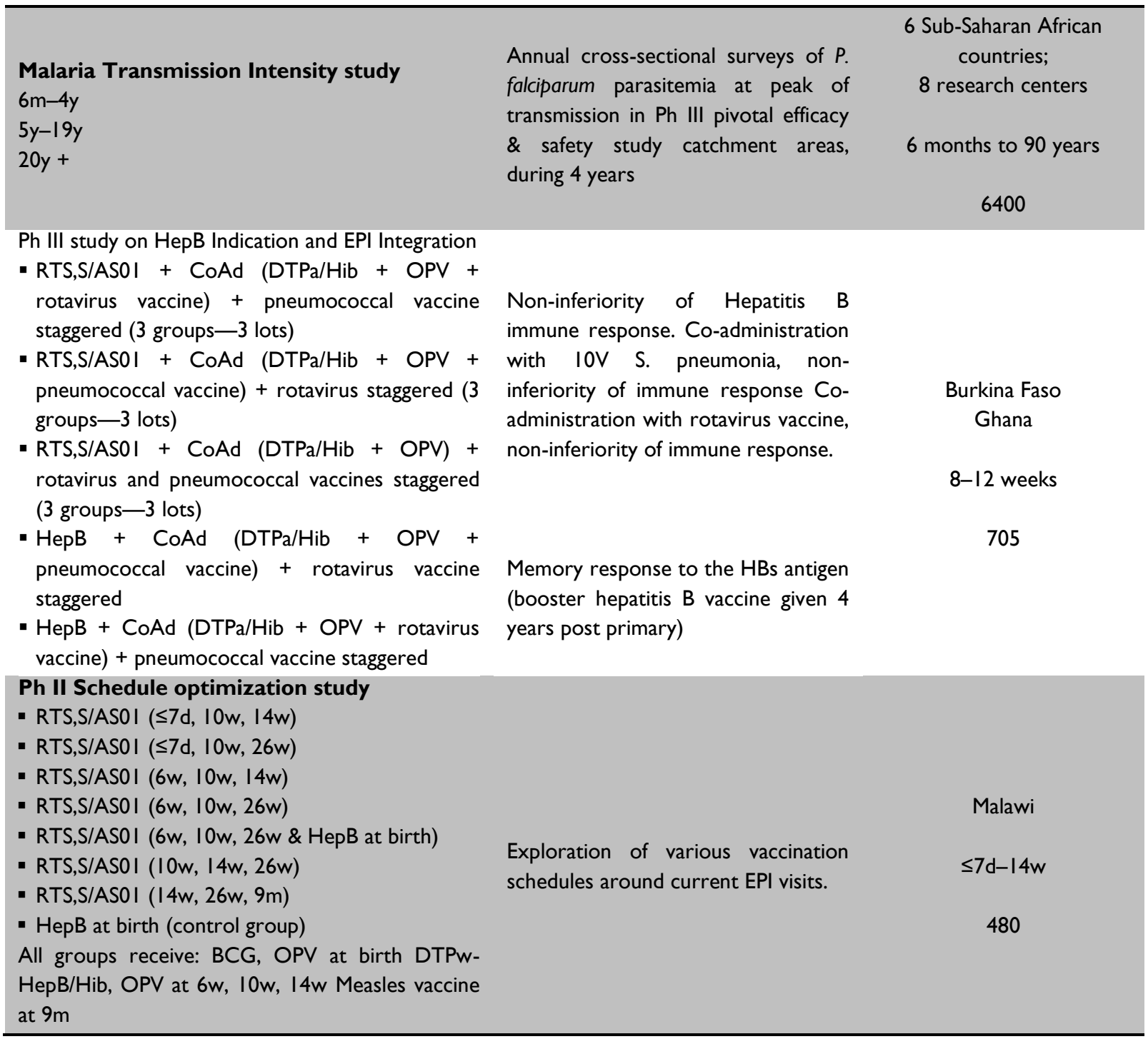

This double-blind, individually randomized, controlled, three-arm trial, in which participants received either three doses of RTS,S one month apart, followed by a booster dose 18 months later; three doses of RTS,S followed by a comparator (or "control") vaccine at the time of booster vaccination; or only control vaccines throughout, had two age categories: young children aged 5-17 months and infants aged 6-12 weeks at the time of enrollment.

Results of the co-primary endpoints of the study after a year of follow-up were published in the New England Journal of Medicine in November 2011 (children aged 5-17 months) and December 20124 (infants aged 6-12 weeks). These results showed that three doses of RTS,S reduced clinical malaria by approximately half in children 5-17 months of age and one-third in infants 6-12 weeks of age, at first vaccination. In a subsequent analysis after 18 months of follow up, children aged 5-17 months at first vaccination with RTS,S experienced $45 \%$ fewer cases of clinical malaria, compared to children immunized with a 
comparator vaccine. Infants aged 6-I2 weeks at first vaccination with RTS,S had $27 \%$ fewer cases of clinical malaria than infants in the control group. Efficacy waned over time in both age categories. These results were achieved on top of existing malaria interventions, which were used by approximately $80 \%$ of the trial participants.

The final study results, which analyzed vaccine efficacy, immunogenicity, safety and impact of RTS,S/ASOI over a median of 38 and 48 months of follow-up (post dose I) in infants and young children, respectively, including the effect of a booster dose of vaccine, were published in The Lancet in April 2015.

These final results demonstrated that vaccination with the 3-dose primary series reduced clinical malaria cases by $28 \%$ in young children and $18 \%$ in infants to the end of the study. A booster dose of RTS,S, administered 18 months after the primary series, reduced the number of cases of clinical malaria in young children (aged 5-17 months at first vaccination) by $36 \%$ and in infants (aged $6-12$ weeks at first vaccination) by $26 \%$ to the end of the study. Administration of the booster dose provided longer term protection against clinical malaria in both groups, with 1774 and 983 cases of malaria averted per 1000 children vaccinated in the older (age 5-17 months) and infant (6-12 weeks) age groups, respectively. The vaccine efficacy waned over time following the booster dose and further studies are ongoing to assess longer term efficacy and the need for additional doses.

RTS,S continued to display an acceptable safety and tolerability profile during the entire phase III study period. In both age categories, adverse events after vaccination included local reactions (such as pain or swelling), which were observed more frequently after RTS,S administration compared to the comparator vaccine. In the younger age category, injection site reactions were reported less frequently after RTS,S administration compared to the standard vaccines routinely used in the African EPI.

The incidence of fever in the week after vaccination was higher in children who received the RTS,S vaccine than in those receiving the comparator vaccine. In some children this resulted in febrile reactions, accompanied by generalized convulsive seizures, but all those affected fully recovered within seven days.

The rates of other serious adverse events seen in the trial were comparable between the trial's RTS,S candidate vaccine recipients and those receiving a control vaccine, except for cases of meningitis, which were reported in low numbers, but more often in the RTS,S group compared to the control. The meningitis signal remained in the older age category, including a small number of new cases reported after the booster dose. This could be a chance finding as comparisons were made across groups for many different diseases, and 
because some of these cases happened years after vaccination without any obvious relationship to vaccination. If RTS,S is licensed, the occurrence of meningitis will be followed closely in post-registration studies. ${ }^{[32]}$

\subsection{Regulatory, Policy, and Financing Pathway}

As an initial step in the policy and regulatory process, GSK submitted a regulatory application to EMA in June 20I4. The RTS,S regulatory application was reviewed under the Article 58 and the CHMP performed a scientific evaluation of RTS,S. In July 20I5, CHMP issued "a European scientific opinion", adopting a positive opinion and recommending the granting of a marketing authorization for active immunization of children aged 6 weeks up to 17 months against malaria caused by $P$. falciparum and against hepatitis $B$, noting that use should be based on official recommendations considering $P$. falciparum malaria epidemiology in different geographical areas. It is important to emphasize that a positive opinion is not licensure or registration in the EU, but provides a scientific opinion that African national regulatory authorities may use in their own regulatory review processes and also plays a critical role in decision making by WHO normative bodies.

Another critical step after WHO recommendation and Prequalification will be decisions by various international financing organizations and public-private partnerships, including Gavi - the Vaccine Alliance (Gavi), and the Global Fund to Fight Aids, Tuberculosis and Malaria (GFATM), to open country support windows for public financing. In preparation for such a decision, Gavi included a malaria vaccine in a recent Vaccine Investment Strategy (VIS) review, an evidence-based prioritization process, undertaken once every five years, to identify new vaccines with high priority for inclusion in the Gavi portfolio. It is anticipated that the Gavi Secretariat will recommend to the Gavi Board the opening of a country support window to the introduction of a vaccine as part of integrated malaria control programs and exploring opportunities for harmonized global procurement strategies with other international financing mechanisms (e.g., GFATM). Given that all clinical trial data from the field are from sub-Saharan Africa and given the scientific opinion adopted by CHMP, it is anticipated that any WHO recommendation, public financing, national regulatory authority review and national policy recommendations on introduction and use of the vaccine will be restricted to sub-Saharan Africa, consistent with the first landmark goal of the MVTRM. ${ }^{[5]}$ 


\subsection{Post-approval Program/Phase IV Studies}

Post-approval studies play an important role in the introduction and scale-up of vaccines and are critical components of any vaccine development program. In the case of RTS,S, the post-approval program is being developed to meet regulatory commitments as part of the EMA Article 58 procedure. It can also be used to provide policy and decisionmakers in-country, with additional information to assist in deciding on the use of a new tool in their national vaccine and malaria control programs. As it relates to pharmacovigilance and impact, three studies are currently envisioned. An epidemiology study (EPI-MAL-002), to "set the baseline" for the incidence of pre-defined diseases that may be reported as adverse events following immunization and for malaria morbidity and mortality. This first phase will be conducted in several countries, and will follow approximately 40,000 children for two years prior to the introduction of RTS,S in the study communities (this phase will start preapproval). This study will be followed by a second phase to be conducted after national regulatory approval of RTS,S, such that RTS,S will be delivered using the immunization system already in place in the study area. The vaccination study (EPI-MAL-003) will enroll another approximately 45,000 children to determine the incidence of these same predefined diseases after immunization with RTS,S. To leverage and further enhance existing infrastructure, these two studies will be conducted at sites that already monitor the population in their catchment area through demographic surveys. $A$ third study (EPI-MAL005), concurrent to the other two studies, will conduct cross-sectional surveys to collect data on the use and coverage of other malaria interventions and will track changes in disease burden during the period in which EPI-MAL-002 and EPI-MAL-003 are conducted. In addition to these studies, the RTS,S post-approval program includes research in health economics and the piloting of communications materials to support possible introduction. ${ }^{[5]}$

\subsection{The Future of RTS,S}

RTS,S, a candidate malaria vaccine, has now been successfully evaluated in a Phase III program conducted in eight African countries and undergone a stringent evaluation by a regulatory agency. Although vaccine efficacy may be modest, the number of cases averted in settings of significant disease burden, be it clinical malaria, severe malaria or malaria hospitalizations, would have a major public health impact. But to do so, all available tools need to be brought to bear in an optimal way to prevent and treat malaria. In the end, the benefit, risk, feasibility and cost-effectiveness will be used to determine the impact of RTS,S. 
The former has initially been evaluated through EMA's Article 58 procedure with a positive opinion for ages 6 weeks to 17 months, noting that subsequent evaluations are still needed by national regulatory authorities. The latter will now be evaluated through policy and financing reviews at the global and national levels. ${ }^{[5]}$

\section{REGULATORY BASIS FOR THE DEVELOPMENT OF A MALARIA VACCINE}

\section{5.l. World health organization (WHO) - Policy Recommendation and Prequalification}

WHO recognizes the importance of malaria due to $P$. falciparum as a major cause of morbidity and mortality, particularly in sub-Saharan Africa, and the essential role of existing malaria control measures in significantly reducing the burden of disease in recent years. Nevertheless prevention needs to be strengthened still further and new tools are needed. ${ }^{\left[{ }^{[8]}\right.}$

The technical group advising WHO on Phase 3 trials of malaria vaccines is the Joint Technical Expert Group (JTEG) on Malaria Vaccines, convened by the Immunization, Vaccines, and Biologicals Department (IVBD) and the Global Malaria Program (GMP), and reporting jointly to Strategic Advisory Group of Experts (SAGE) on immunization and the Malaria Policy Advisory Committee (MPAC). Based on the positive opinion adopted by CHMP, JTEG's evaluation of RTS,S was considered jointly by SAGE and MPAC who advised WHO on recommendation(s) for use. WHO will also consider RTS,S for prequalification $(P Q)$, a process "intended to ensure that a specific vaccine from a specific manufacturer meets international standards of quality, safety and efficacy and is appropriate for the target population. Only WHO prequalified vaccines can be supplied to countries through UN agencies". [5]

The RTS,S/ASOI vaccine has been evaluated in a large Phase 3 trial, and received a positive regulatory assessment. However, a number of uncertainties need to be resolved in order to assess the advisability of introducing the RTS,S/ASOI vaccine for routine use, such as: if the protection demonstrated in children aged 5-17 months can be replicated in the context of routine health systems; the fact that vaccine efficacy in the younger age category (6-I2 weeks) was found to be low; the extent to which RTS,S/ASOI vaccination impacts allcause mortality and; whether the excess cases of meningitis and cerebral malaria identified are causally related to RTS,S/ASOI vaccination. 
WHO recommends that the pilot implementations use the 4-dose schedule of the RTS,S/ASOI vaccine in 3-5 distinct epidemiological settings in sub-Saharan Africa, at subnational level, covering moderate-to-high transmission settings. These pilot implementations should be done with phased designs and in the context of ongoing high coverage of other proven malaria control measures.

The pilot implementations should involve sufficiently large populations, followed for an adequate duration, with rigorous evaluation, to allow the following: assessment of operational feasibility of providing the malaria vaccine in the target age-group at the recommended 4-dose schedule in the context of health service delivery in various countries; evaluation of the impact of the vaccine on child mortality, including measures to determine the impact of the vaccine when added to concomitant malaria interventions; surveillance for adverse events following vaccination, with an emphasis on meningitis and cerebral malaria including by sex and using standardized case definitions; and systematic compilation of evidence on the functioning of the immunization programme, adherence to currently recommended malaria control measures, and broader health system functioning and community engagement, including evidence of any adverse effects of vaccine implementation on other malaria control measures.

In the pilot implementation schedules, the malaria vaccine should be given as a 3-dose initial series with a minimum interval between doses of 4 weeks, followed by a 4 th dose at 15-18 months after the 3rd dose. The Ist dose should be administered as close as possible to age 5 months and the 3 rd dose should be completed by 9 months of age. RTS,S/ASOI can be co-administered with other vaccines in the national immunization programme.

Prior to any pilot implementation, appropriate training and communication materials for the general public and for health workers should be developed and disseminated with particular emphasis on the incomplete protection conferred by the vaccine and hence the need to continue to use other malaria control measures and to seek health care promptly in the case of fever, as well as the importance of ensuring that the child receives all 4 doses of the vaccine. Also, a series of research recommendations were made by the principal WHO policy advisory committees for immunization and malaria. These include exploration of alternative schedules and other strategies to improve the effectiveness of the RTS,S vaccine. ${ }^{[8]}$ 


\subsection{European Medicines Agency (EMA) - Article 58 Procedure}

Article 58 is a specific legal basis in the European pharmaceutical legislation, allowing EMA to perform an evaluation of medicinal products which are intended to be used only outside the EU to prevent or treat diseases of major public health significance. The same processes are used by EMA as those used for EU medicinal products. This evaluation is performed by $\mathrm{WHO}$ and with involvement of the relevant national regulatory authorities. RTS,S/ASO I will be submitted to EMA under article 58 because it is being developed by an EU manufacturer specifically for targeted populations and against a disease which occurs primarily outside the EU. ${ }^{[33]}$

Based on the CHMP review of data on quality, safety and efficacy, it was considered by consensus that the risk-benefit balance of RTS,S for active immunization of children aged 6 weeks up to 17 months against malaria caused by Plasmodium falciparum and against hepatitis $B$ is favorable. ${ }^{[34]}$

\subsection{Global Strategies to implement a Malaria Vaccine}

In order to bring a malaria vaccine to all people, marketing authorizations are needed in each country in which the vaccine should be used. Diverse strategies are possible to achieve this goal (Table 5). The EPI using WHO prequalified vaccines has most successfully brought vaccines to many people globally. As per guidance "Assessing the Programmatic Suitability of Vaccine Candidates for WHO Prequalification" can be started after a positive article 58 scientific opinion has been granted or a national MA has been granted in the country of vaccine manufacturing. If the manufacturing company is a US company, a FDA orphan drug MA can be applied first and the authorized vaccine is then automatically listed as a prequalified vaccine. If the manufacturer is in the $\mathrm{EU}$, the prequalification follows a positive scientific opinion after an article 58 process. ${ }^{[35]}$

Table 5 - Strategies to globally implement a malaria vaccine ${ }^{[35]}$

\begin{tabular}{cc}
\hline Vaccine Manufacturer & Global Process Plan Outline \\
\hline EU & $\begin{array}{c}\text { Article } 58 \rightarrow \text { Prequalification } \rightarrow \text { National processes } \\
\text { Orphan Drug } \rightarrow \text { Prequalification } \rightarrow \text { National processes }\end{array}$ \\
US & FDA ODA $=$ Prequalification $\rightarrow$ National processes \\
$\begin{array}{c}\text { Country other } \\
\text { than US/EU }\end{array}$ & Manufacturer country approval $\rightarrow$ Prequalification $\rightarrow$ National \\
Processes & Potential parallel processes: \\
Orphan Drug Approval US-EMA \pm Local RA, EMA Article $58-$ FDA ODA, Prequalification - Local RA
\end{tabular}




\section{CONCLUDING REMARKS}

Malaria remains one of the most devastating infectious diseases affecting those living in tropical areas of the world. To date, vaccination is the most effective method of preventing infectious diseases and represents the greatest contribution of immunology to human health. Recent advances have led to a new era of vaccine development in general and for malaria in particular. Adjuvants and vaccine delivery systems are becoming increasingly more important for the development of a new generation of vaccines, combining different types of adjuvants into antigen-specific formulations with greater efficacy and improved vaccine formulations. These new approaches offer a wide spectrum of opportunities in malaria vaccine research with direct applications for the near future. ${ }^{[3]}$

The positive results with the Phase III trial of RTS,S have established that a vaccine against malaria can provide partial protection to children in endemic areas, but its limited efficacy and relatively short window of protection mandate that new generations of more efficacious vaccines must be sought. Difficulties towards developing an effective vaccine include the biological complexity of the organism with an array of stage-specific genes many of which in the erythrocytic stages are antigenically diverse. Most vaccine studies have focused on a single or a few antigens with an apparent functional role, but this is likely to be too restrictive. Broad, multi-antigen, multi-stage immune responses based on an understanding of biological responses are needed. ${ }^{[36]}$

Malaria vaccines are expected to be an important addition to the arsenal of tools in the future. Several vaccine candidates, with different modes of action, are currently in vrious stages of development to prevent $P$. falciparum and $P$. vivax infections. At least one of these (RTS,S) is close to licensure and review for policy recommendation. The global health community has called for the development and licensing, by 2030 , of malaria vaccines with protective efficacy of at least $75 \%$. Malaria vaccines are currently envisaged as a complementary tool that should not replace the core package of interventions. ${ }^{[3]}$ 


\section{BIBLIOGRAPHY}

[I] - WHO - Media Centre. Malaria Fact Sheet - [Online] [Accessed on $5^{\text {th }}$ May 2016. Last Updated April 2016]. Available at: http://www.who.int/mediacentre/factsheets/fs094/en/

[2] - WASSMER, Samuel C. et al. - Investigating the Pathogenesis of Severe Malaria: A Multidisciplinary and Cross-Geographical Approach. The American Society of Tropical Medicine and Hygiene. Vol. 93 (Suppl 3), (20I5) p. 42-56.

[3] - C., Arama; M., Troye-Blomberg - The path of malaria vaccine development: challenges and perspectives. Jornal of INTERNAL MEDICINE. Vol. 275 (5), (20I4) p. 456-466

[4] - HOFFMAN, Stephen L.; VEKEMANS, Johan; THOMAS, Richie L.; DUFFY, Patrick E. The march toward malaria vaccines. Review Article. Vaccine, Vol. 33, Supplement 4, (20I5), p. DI3-D23

[5] - KASLOW, David C.; BIERNAUX, Sophie - RTS , S: Toward a first landmark on the Malaria Vaccine Technology Roadmap. Vaccine. Vol. 33 (52), (20I5) p. 7425-7432.

[6] - WHO - World Malaria Report 2015 - [Online] [Accessed on $5^{\text {th }}$ May 2016] Available at: http://apps.who.int/iris/bitstream/I0665/2000I8/I/978924I565I58_eng.pdf

[7] - BIRKETT, Ashley J. - Status of vaccine research and development of vaccines for malaria. Vaccine. Vol. 34 (26), (2016) p. 29I5-2920.

[8] - WHO STRATEGIC ADVISORY GROUP OF EXPERTS ON IMMUNIZATION (SAGE); WHO MALARIA POLICY ADVISORY COMMITTEE (MPAC) - Weekly epidemiological record. 4 (2016) 33-52.

[9] - BIRKETT, Ashley J. - Building an effective malaria vaccine pipeline to address global needs. Vaccine. Vol. 33 (52), (20I5) p. 7538-7543.

[10] - HISAEDA, H., YASUTOMO, K. \& HIMENO, K. - Malaria: Immune evasion by parasites. Int. J. Biochem. Cell Biol. Vol. 37, (2005) 700-706 
[II] - MOORTHY, Vasee S.; GOOD, Michael F.; HILL, Adrian V. S. - Malaria vaccine developments. The Lancet. Vol. 363 (2004), p. I50-I56.

[12] - WHO EXPERT COMMITTEE ON BIOLOGICAL STANDARDIZATION - Annex 3 Guidelines on the quality, safety and efficacy of recombinant malaria vaccines targeting the pre-erythrocytic and blood stages of Plasmodium falciparum [Online] [Accessed on 12 $12^{\text {th }}$ May 2016] Available at: http://www.who.int/biologicals/vaccines/Malaria_Guidelines_TRS_980_Annex_3.pdf

[13] - SAUERWEIN, R. W.; BOUSEMA, T. - Transmission blocking malaria vaccines: Assays and candidates in clinical development. Vaccine. Vol. 33 (52), (20I5) p. $7476-$ 7482

[14] - GARCÍA-BASTEIRO, A. L., BASSAT, Q. \& Alonso, P. L. - Approaching the target: The path towards effective malaria vaccine. Mediterr. J. Hematol. Infect. Dis. Vol 4, (2012) p. 3-4

[15] - MUELLER, Ivo; RUSHDI, Ahmad; CHITNIS, Chetan E. - Development of vaccines for Plasmodium vivax malaria. Vaccine. Vol. 33 (52), (20I5) p. 7489-7495.

[16] - YADAVA, A. et al. - A novel chimeric Plasmodium vivax circumsporozoite protein induces biologically functional antibodies that recognize both VK2 I 0 and VK247 sporozoites. Infect. Immun. Vol. 75, (2007), p. I I77-II 85

[17] - HERRERA, S. et al. - Use of long synthetic peptides to study the antigenicity and immunogenicity of the Plasmodium vivax circumsporozoite protein. Int. J. Parasitol. Vol. 34, (2004), p. 1535-1546

[18] - BAUZA, K. et al. - Efficacy of a Plasmodium vivax malaria vaccine using ChAd63 and modified vaccinia ankara expressing thrombospondin-related anonymous protein as assessed with transgenic Plasmodium berghei parasites. Infect. Immun. Vol. 82, (20I4), p. I277-1286

[19] - WU, Y. et al. - Phase I trial of malaria transmission blocking vaccine candidates Pfs25 and Pvs 25 formulated with montanide ISA 5 I. PLoS One. Vol 3, (2008) 
[20] - RICHIE, Thomas L. et al. - Progress with Plasmodium falciparum sporozoite (PfSPZ) -based malaria vaccines. Vaccine. Vol. 33 (52), (20I5) p. 7452-746I.

[2I] - SAGARA I, DICKO A, E. R. et al. - A randomized controlled phase 2 trial of the blood stage AMAI-CI/Alhydrogel malaria vaccine in children in Mali. Vaccine. Vol. 23, (2009), p. 3090-3098

[22] - EL SAHLY, H. M. et al. - Safety and immunogenicity of a recombinant nonglycosylated erythrocyte binding antigen 175 region II malaria vaccine in healthy adults living in an area where malaria is not endemic. Clin. Vaccine Immunol. 17, (2010) p. 1552-1559 (2010).

[23] - ESEN, M. et al. - Safety and immunogenicity of GMZ2 - a MSP3-GLURP fusion protein malaria vaccine candidate. Vaccine. 27, (2009) p. 6862-6868

[24] - HERMSEN, C. C. et al. - Glutamate-rich protein (GLURP) induces antibodies that inhibit in vitro growth of Plasmodium falciparum in a phase I malaria vaccine trial. Vaccine 25, (2007) 2930-2940

[25] - OGUTU, B. R. et al. - Blood stage malaria vaccine eliciting high antigenspecific antibody concentrations confers no protection to young children in Western Kenya. PLoS One 4, (2009)

[26] - GENTON, B. et al. - A recombinant blood-stage malaria vaccine reduces Plasmodium falciparum density and exerts selective pressure on parasite populations in a phase I-2b trial in Papua New Guinea. J. Infect. Dis. I85, (2002) $820-827$

[27] - CACHAT, M. et al. - Phase I Malaria Vaccine Trial with a Long Synthetic Peptide Derived from the Merozoite Surface Protein 3 Antigen. Society 73, (2005) $8017-8026$

[28] - JEPSEN, M. P. G. et al. - The malaria vaccine candidate GMZ2 elicits functional antibodies in individuals from malaria endemic and non-endemic areas. J. Infect. Dis. 208, (2013) 479-488

[29] - HORII, T., SHIRAI, H. \& JIE, L. - Evidences of protection against blood-stage 
infection of Plasmodium falciparum by the novel protein vaccine SE36. Parasitol. Int. 59, (2010) 380-386

[30] - PALACPAC, N. M. Q. et al. - Phase Ib Randomized Trial and Follow-Up Study in Uganda of the Blood-Stage Malaria Vaccine Candidate BK-SE36. PLoS One 8, (20I3)

[3I] - NAHRENDORF, Wiebke et al. - Cross-stage immunity for malaria vaccine development. Vaccine. Vol. 33 (52), (20I5) p. 75I3-75I7

[32] - MVI; GSK - Fact sheet: The RTS,S Malaria Vaccine Candidate (Mosquirix TM) [Online] [Accessed on $15^{\text {th }}$ June 2016] (2015), Available at: http://www.malariavaccine.org/files/MVI-GSK-RTSSfactsheetFINAL-web.pdf

[33] - GATES, M. - WHO: Questions and Answers on Malaria Vaccines. October (2013) I-4. [Online] [Accessed on 16 ${ }^{\text {th }}$ May 2016] Available at: http://apps.who.int/vaccine_research/development/WHO_malaria_vaccine_q_and_a_Oct20 13.pdf

[34] - EMA - Assessment report [Online] [Accessed on $16^{\text {th }}$ May 2016] Available at: http://www.ema.europa.eu/docs/en_GB/document_library/Other/2015/I0/WC500194577.pd $f$

[35] - BURRACK, Sarah - Status, challenges and regulatory strategies to develop a malaria vaccine [Online] [Accessed on 25 th May 2016]. [S.I.] : University Bonn (Germany), (20I3), Available at: http://dgra.de/media/pdf/studium/masterthesis/master_burrack_s.pdf

[36] - LONG, Carole A.; ZAVALA, Fidel - Malaria vaccines and human immune responses. Current opinion in microbiology. Vol. 32, (2016) p. 96-102.

[37] - WHO - Global technical strategy for malaria 20 I6-2030. [Online] [Accessed on $15^{\text {th }} \quad$ June 2016], (2015), Available at: http://www.who.int/malaria/areas/global_technical_strategy/en/ 